\title{
O POTENCIAL DIDÁTICO DOS APLICATIVOS DE ACESSIBILIDADE NA EDUCAÇÃO INCLUSI- VA
}

\author{
THE DIDACTIC POTENCIAL OF ACCESSIBILITY APP IN INCLUSIVE EDUCATION
}

Larissa Buenaño Ribeiro

\begin{abstract}
Esta pesquisa tem como objetivo principal adaptar ao contexto educacional inclusivo um serviço de design enquanto gestor de informações e conhecimentos sobre usos e experiências de aplicativos de acessibilidade como recursos didáticos. Optou-se, no entanto, por uma metodologia exploratório-explicativa a respeito da interatividade na educação e do potencial de aprendizagem dessas ferramentas. Já os resultados esperados apontam para mais projetos com responsabilidade social, voltados para a interdisciplinaridade e para a política educacional na inclusão.
\end{abstract}

Palavras chave: Design, Educação Inclusiva, Aplicativos.

This research has as main objective to adapt to the inclusive educational context a design service as manager of information and knowledge about uses and experiences of accessibility applications as didactic resources. However, it was opted for an exploratory-explanatory methodology regarding interactivity in education and the learning potential of accessibility applications. The expected results point to more projects with social responsibility, focused on interdisciplinarity and on educational policy in inclusion.

Palavras chave: Design, Inclusive Education, App`s. 


\section{Tendências e perspectivas de inclusão na aprendizagem móvel}

A mobile-learning é associada a qualquer tecnologia móvel utilizada na educação, entretanto, serão aqui destacados os smartphones e tablets como suportes para os aplicativos educacionais. Segundo a UNESCO (2013), a definição da mobile-learning constitui-se na aprendizagem móvel que abrange o uso de tecnologia móvel isoladamente ou em combinação com qualquer outra tecnologia de informação para facilitar a aprendizagem a qualquer hora, em qualquer lugar. É Importante ressaltar neste momento, que para estabelecer uma definição de mobile-learning não podem ser ignorados três conceitos que direcionam sua aplicação: as tecnologias móveis; a ubiquidade ligada à mobilidade; e os usos educacionais em contextos variados.

Habilitação em Projeto de ProdutoUniversidade do Estado do Pará (UEPA); Mestranda em Tecnologias da Inteligência e Design Digital- Pontifícia Universidade Católica de São Paulo (PUC-SP).
Suas áreas de pesquisa e experimentação evoluem paralelamente as tecnologias dos próprios dispositivos móveis. Conforme a tecnologia avança, o interesse a explorar potenciais usos educacionais também evolui. Evidencia-se então, um grande potencial para o desenvolvimento de aplicações com a finalidade de adaptar e criar novos métodos de ensino e aprendizagem inserindo docentes e alunos com necessidades educacionais especiais nessa nova realidade de inclusão tecnológica.

Em relação as suas aplicações nas aulas, Silva (2015) afirma que os currículos escolares deveriam ser capazes de dar oportunidades para os alunos questionarem as formas de dominação presentes nas salas de aula. Uma política pedagógica deve não somente celebrar e reconhecer a diferença e a identidade de cada aluno, mas, principalmente questioná-las, induzindo o currículo escolar a conter estratégias que coloquem a estabilidade e a potencialidade das identidades em pauta.

É através das maneiras que se escolhe olhar para o currículo e para a educação escolar que Costa (2011) explica como se forma uma representação da realidade e como que se vai direcionar as condutas e construir as suas subjetividades. Posto isso, o poder de fornecer ferramentas para os sujeitos se inventarem e reinventarem no processo de ensino e de aprendizagem precisa ser avaliado com cautela.

Facilitar o acesso e reinventar a vida das pessoas portadoras de deficiências tem sido uma preocupação tecnológica que vem tentando ser sanada pelos recursos de acessibilidade do iOS e Android presentes nos dispositivos móveis. Encontram-se nesses softwars aplicativos de acessibilidade que permitem interações que vão da diversão à funcionalidade, e porque não estender sua utilização na educação?
Pretende-se nesta discussão fundamentada em tecnologias para comunicação e para o desenvolvimento de habilidades na educação inclusiva, fazer um recorte explicativo dos aplicativos que já vêm instalados nesses dispositivos dentre outros que estimulam práticas solidárias e colaborativas, os quais apresentam configurações de acessibilidade que podem ser espontaneamente utilizadas como facilitadores do aprendizado e da comunicação entre professores e alunos com necessidades educacionais especiais.

Nunca se viu tantas maneiras diferentes de se estabelecer a comunicação e um possível aprendizado, seja você cego, surdo, tenha restrições físicas e motoras, ou até lide, cotidianamente com pessoas assim, a iOS, enxergando em todos os sentidos, apresenta para esse grupo especifico de usuários uma série de aplicativos que tem usabilidades mais simples do que tocar em uma tela, ou melhor, nem isso.

Para o público referente às necessidades visuais, temos o VoiceOver, um aplicativo que já vem no iPhone, iPad e iPod, ele consiste em um leitor de tela, tendo disponível em mais de 30 idiomas, basta tocar na tela para ouvir o que está sob ou seu dedo e usar movimentos para navegar e controlar seu dispositivo. Já a Siri, assistente inteligente da Apple, quando está vinculada ao VoiceOver, pode enviar mensagens, fazer ligações, agendar reuniões e até responder onde fica a biblioteca mais próxima, tudo por comando de voz. Esse sintetizador de voz pode também ler os textos e provas dos alunos cegos, se o material se comprometer em descrever todos os elementos da atividade e principalmente colocar legendas nas imagens.

Outro facilitador na mesma linha de raciocínio é o Ditado, no qual você pode falar ao invés de digitar, apenas tocando no botão do microfone no teclado, ao dizer o que gostaria de escrever, seu dispositivo transforma sua oratória em texto. O Zoom, que funciona como lente de aumento, chega a aumentar a visualização de $100 \%$ a $1500 \%$ e acessar diversas opções de filtros de acordo com o grau de baixa visão, este aplicativo também se relaciona com o VoiceOver, para que o usuário possa ver ou ouvir melhor o que estiver acontecendo em sua tela, além disso, o app permite inverter cores, reduzir o ponto branco, ver em escala de cinza ou aplicar filtros de cor para ajudar usuários com daltonismo bem como outros problemas visuais, podendo selecionar um ajuste predefinido ou configurar com precisão o tom e a matiz de cor para atingir a visualização mais adequada para a atividade elaborada pelos professores.

Para os com dificuldades auditivas, as chamadas pelo FaceTime são uma boa opção, pois deixam que você capte cada movimento e expressão facial, com recursos de vídeo de alta qualidade, sendo 
ideal para a comunicação pela linguagem de sinais. Neste caso, se os professores obtiverem domínio em libras, podem tirar as dúvidas de seus alunos ou manter contato com eles dentro e fora da sala de aula.

O áudio mono, também agrega na audição acessível, visto que você pode perder parte do áudio se apresentar alguma necessidade em um dos lados, devido às gravações em estéreo, normalmente, terem trilhas distintas no canal direito e esquerdo do áudio, ao se fundamentar nessa prática de usar fones de ouvido, o aplicativo pode ajudar reproduzindo os dois canais de áudio em ambos os ouvidos, permitindo ajuste e balanço para o melhor uso. Outros elementos relevantes na utilização abrangente do iOS para deficientes auditivos são os alertas visíveis e vibratórias, onde pode-se configurar uma luz de LED para que ela pisque informando sobre chamadas e alertas recebidas, estendo-se também para informar o tempo destinado para alguma atividade ou informar sobre inícios e términos de aulas, além de escolher entre os vários padrões de vibração ora criar um. Já a outra função interessante e também presente no sistema operacional, são as chamadas legendas ocultas, encontradas pelo ícone "Legendado" nos filmes da iTunes Store, ou pelos podcasts com legendas no iTunes U. Baixa-se direto para o iPhone e se é permitido por esta ferramenta assistir aos filmes com legendas especializadas. O iOS também aceita legendas abertas que podem ser personalizadas com diversos estilos e fontes.

Já para os com dificuldades físicas e motoras existe o "Controle Assistivo" que é uma tecnologia capaz de navegar em sequência pelos itens da tela e realizar ações específicas usando vários tipos de controles ativados por Bluetooth. O recurso pode ser personalizado para usuários iniciantes ou avançado, permitindo-os simplificar ações existentes ou criar novas ações. O Assistivetouch, também destinado para esse público em questão é muito intuitivo e fácil de usar. Com ele os usuários conseguem adaptar a tela Multi-Touch às suas necessidades físicas, por exemplo, pessoas com dificuldades em alguns movimentos, como juntar e separar os dedos podem escolher outros meios mais acessíveis, como apenas dar um toque no aparelho com movimentos de seu alcance físico motor.

Dentre tantos recursos de acessibilidade encontrados no sistema iOS, é de extrema importância falar sobre o Acesso Guiado, direcionado para pessoas com autismo e outros déficits de atenção. Com esse aplicativo, um familiar, professor ou terapeuta pode restringir um dispositivo com iOS a um determinado aplicativo e limitar seu tempo gasto, de forma que os movimentos e toques aleatórios não interfiram no seu uso e no seu aprendizado.
Apesar de apresentar menos funções de acessibilidade que as encontradas no iOS, o sistema Android vem com o TalkBack que chega pré instalado nos dispositivos móveis, e é direcionado para facilitar a vida dos portadores de necessidades especiais visuais, implementando respostas faladas, audíveis e por vibração aos smartphones ou tablets.

Além dos exemplos que já vem instalados nos dispositivos móveis, encontram-se nas lojas online do Android e do iOS outros aplicativos de destaque para inclusão tais como: Shades, aplicativo que reduz o brilho da tela; BrailleBack, aplicativo que mescla o suporte de voz do TalkBack com o braile, possibilitando também a conexão de dispositivos de braile com o telefone via Bluetooth sendo a informação da tela do telefone transferida e convertida em braile; Rock Lock, uma espécie de reprodutor de música adaptado; Eyes-free Project, para pessoas com baixa visão ou redução da capacidade visual; Magnify, que converte o telefone em lupa; BiggerIcons, que muda o tamanho dos ícones; LCD Density Modder, capaz de reduzir a intensidade do brilho da tela e tornar todos os ícones maiores; Ubook, livros em áudio; Hand Talk, aplicativo que traduz automaticamente textos e áudios para a língua de sinais; Livox, uma plataforma personalizável para pessoas com deficiência.

Com o investimento nesses aplicativos, é possível aumentar o alcance aos produtos de entretenimento dos smartphone ou tablets, bem como escutar uma música no Spotfy por comando de voz ou assistir um filme com legenda especializada no Netflix. Outro aplicativo que não foi idealizado para deficientes, mas que acabou atingindo de forma positiva esse público foi o RunKepper, muito utilizado para deficientes visuais que praticam esportes, funcionando como uma assistente que fala todos os detalhes sobre o exercício físico acompanhado do GPS.

Para dar continuidade a essa listagem de alguns aplicativos de acessibilidade, vamos nos adentrar em dois que estimulam práticas solidárias exatamente de acordo com as possíveis práticas que serão incentivadas nessa pesquisa, tanto o "Be My Eyes" quanto o "Guia de Rodas" são feito uma rede social de solidariedade, que unem pessoas com visão e mobilidade perfeitas com pessoas com deficiências visuais ou de mobilidade, a partir de uma simples mudança comportamental.

O “Be My Eyes” funciona através de uma vídeo chamada inspirada no Facetime da iOS, na qual a pessoa com visão normal empresta seus olhos ao descrever o que se encontra na tela, auxiliando assim, várias tarefas cotidianas. Nesse caso, você pode ajudar lendo bulas de remédios, descrevendo possíveis obstáculos que possam ser resolvidos em 
poucos segundos, mas que já são de grande valia em uma rotina de quem enxerga pouco ou nada. Ao entrar no aplicativo, você escolhe se é um voluntário ou um deficiente visual - no segundo caso, o app oferece toda a acessibilidade necessária para se conectar à outra pessoa - e aguarda até que um pedido de ajuda seja enviado. As orientações do voluntário são feitas por escrito e o aplicativo consegue lê-las em voz alta para a pessoa com deficiência visual. Incentivando assim, a cooperação e a aproximação entre os alunos nas atividades em sala de aula, buscando demonstrar que em grupo, todos podem se ajudar e contribuir com suas habilidades nas tarefas exigidas pelos professores.

Já o Guia de Rodas identifica e promove informações de acessibilidade para pessoas com dificuldade de locomoção visando uma vida mais autônoma e inclusiva. A sua conscientização é feita através da produção de conteúdo próprio, com abordagem sobre a causa da acessibilidade e da comunicação nas redes sociais, permitindo que os usuários avaliem e busquem por estabelecimentos acessíveis no mundo todo. A qualificação dos estabelecimentos acessíveis é feita através do Selo $\square$ guia de rodas $\square$ de edificações. Sua metodologia de avaliação consiste numa análise dos seus $\square$ guia de rodas $\square$ que alia o conhecimento técnico de arquitetos especializados a vivencia prática de pessoas com dificuldade de locomoção. Essa combinação entre teoria e prática, possibilita o desenvolvimento de soluções inteligentes e eficazes de acessibilidade. Após a visita e a análise, é elaborado um relatório com sugestões de mudanças, caso necessárias, e um parecer da equipe sobre as condições de acessibilidade do edifício ou caminho em questão e por fim, uma placa, em reconhecimento da experiência acessível da edificação. Esse selo seria ideal para avaliar tantos as condições estruturais das escolas, quanto os caminhos das casas dos alunos mobilidade reduzida até as suas respectivas salas de aula.

Agora imaginem só os professores numa rede solidária em prol de melhorias na educação inclusiva, inserindo sua visão, seu ouvido, suas experiências e seus saberes nas práticas das aulas inclusivas, respaldados por esses recursos tecnológicos que podem incluir e contribuir muito para o aprendizado dos portadores de necessidades especiais, compartilhando seus resultados de desenvolvimento e estimulando mais e mais professores a buscarem ferramentas que otimizem a comunicação e a produtividade das aulas no contexto da inclusão.

A título de curiosidade, essa pequena passagem teórica perpassou por vários aplicativos de acessibilidade que podem ser postos em prática para a viabilização de aulas mais inclusivas, ressaltando o quanto que as pesquisas tecnológicas se preocupam com a inclusão digital, entretanto, é constatado a falta de publicidade ou interesse diante dessas ferramentas, elas infelizmente não tem tanta atenção como uma atualização de What$s A p p$, aplicativo mais popular do Brasil, que troca mensagens, áudios e vídeo chamadas sem pagar nada, áudios e vídeos esses, que podem se estender também a comunicação de deficientes visuais e auditivos.

Esse fato não é por falta de público alvo, já que de acordo com a pesquisa realizada pelo Instituto Brasileiro de Geografia e Estatística (IBGE), aproximadamente 24,6 milhões de pessoas ou 14,5\% da população total apresentam algum tipo de incapacidade ou deficiência. É decorrente, hipoteticamente, da falta de costume, do desconhecimento e da ausência de prática em implantar esses aplicativos de acessibilidade no cotidiano e na educação.

Nesse sentido, essas ferramentas tecnológicas abrem oportunidades para os designers recomendarem ações de ensino e aprendizagem, compreendendo de que maneira a informação pode ser processada e apresentada de forma criativa em um contexto social mais inclusivo, abrem também, oportunidades para pessoas consideradas "fora dos padrões", cujo processo de aprendizado não segue a lógica convencional, virarem consumidores assíduos desses aplicativos e criarem sua lógica de aprendizado, abrindo mais ainda, a oportunidade de professores, como uma pequena mudança comportamental, serem, além de consumidores dessas ferramentas, os olhos de alguém, os ouvidos e os formadores de conhecimento de todos os seus alunos.

\section{Critérios de auxílio para aplicativos na educação inclusiva}

Para fazer dos aplicativos educacionais uma proposta pedagógica inclusiva se faz essencial levantar os principais conceitos e abordagens aplicados no contexto da aprendizagem móvel - m-learning. Descrevendo os critérios de auxílio e usabilidade específicos para esta modalidade, tanto quanto uma revisão de literatura dos principais atributos de qualidade que podem compor uma metodologia específica para avaliação e disseminação de experiências educacionais com alunos especiais.

O ponto principal a ser levado em consideração é a importância da interatividade usual e da efetivação da comunicação no aprendizado por meio desses aplicativos, visto que essas ferramentas que auxiliam na educação inclusiva devem apresentar critérios e recursos digitais funcionais, tanto nas interfaces quanto nos conteúdos multimídia, categorizados em 
listas de verificação por meio de testes de uso.

Os aplicativos educativos de acordo com os critérios de qualidade devem ter características fundamentais para sua boa aplicabilidade e usabilidade que ocasionem no melhor desempenho do processo de ensino e de aprendizagem, devem, além disso, instigar as habilidades cognitivas de seus alunos e, acima de tudo, proporcionar situações para que possam utilizar seus novos conhecimentos na solução de problemas e tarefas cotidianas.

Propõe-se, para isso, uma categorização dos critérios de qualidade de um aplicativo a partir de duas vertentes avaliativas que direcionarão as sugestões pedagógicas, são elas: a avaliação formativa, que ocorre durante o desenvolvimento da solução educacional, atuando como um "controle de qualidade" diante das características embasadas em teorias e normas de usabilidade; e a avaliação somativa, que acontece no final de um período ou curso, com a finalidade de identificar como os alunos reagiram aos novos métodos de ensino e aprendizagem utilizados.

Ao buscar respostas para as necessidades dos alunos especiais em aplicativos criteriosamente identificados, estaremos também, mapeando as potencialidades e as dificuldades dos alunos em diferentes níveis, respeitando cada diversidade e as segmentando por deficiência. Este mapeamento pode orientar ações e estratégias de inovação que se adaptem a várias escolas, auxiliando nas aulas inclusivas e planejando formas de estimular e dialogar favoravelmente as relações que se constituem em torno dos aplicativos, dos professore e dos alunos com necessidades educacionais especiais.

Pesquisar sobre esses critérios em bens e serviços educacionais de inclusão faz mais sentido quando mencionamos os princípios de usabilidade bem definidos pelo Design Universal, que emprega esse acesso ao conhecimento através da diversidade, ao indicar elementos que possibilitam o uso equitativo dos produtos e serviços.

A usabilidade conceituada no Design Universal, conforme Martins et al. (2000), refere-se à ampla dimensão entre o usuário e o produto ou serviço, atento ao seu espaço dinâmico, o consumidor, no caso, pode facilmente aprender a utilizar, de forma segura e eficaz, produtos ou serviços com os quais ainda não havia tido contato.

O Design Universal ou design para todos, diz respeito, pontualmente, ao desenvolvimento de produtos e serviços que possam ser usados pela maior extensão possível de pessoas, valendo-se dos seguintes princípios publicados pelo Center for Universal Design dos Estados Unidos, Story (2000): Uso equitativo, no qual o design é útil para pessoas com habilidades diversas; Flexibilidade de uso, quando o design acomoda uma variedade de preferências e habilidades individuais; Uso simples e intuitivo, decorrente da facilidade de entender, independente da experiência, do conhecimento prévio e das habilidades linguísticas dos usuários; Informação perceptível, nesse princípio o design comunica a informação necessária efetivamente aos usuários, independente das condições ou habilidades sensoriais; Tolerância ao erro, que acontece quando o design minimiza perigos e consequências adversas de ações acidentais ou intencionais; Baixo esforço físico, se tratando do uso eficiente, confortável e com o mínimo de fadiga; Espaço, que acontece quando o tamanho do corpo, postura e mobilidade dos usuários são apropriados.

Sob este mesmo enfoque dado a importância da usabilidade em tecnologias para a educação, o grupo de normas NBR ISO/IEC 9126 enumerou cinco características que descrevem a qualidade de um software sob várias perspectivas: Qualidade de uso, capacidade do produto de software de permitir que usuários especificados atinjam metas com eficácia, produtividade, segurança e satisfação em contextos de uso específicos; Eficácia, capacidade de permitir que seus usuários atinjam metas em um contexto de uso determinado; Produtividade, capacidade de conceder que seus usuários empreguem a quantidade apropriada de recursos em relação à eficácia obtida, nesses recursos pode-se incluir o tempo para completar a tarefa, o esforço do usuário, os materiais ou os custos financeiros utilizados; Segurança, capacidade de apresentar níveis aceitáveis de riscos de danos a pessoas, negócios, software, propriedades ou ao ambiente; Satisfação, que é a resposta do usuário à interação com o produto e inclui atitudes relacionadas ao uso do produto.

Delimitar tantos critérios de usabilidade e qualidade para aplicativos educacionais implica, dentre outras ações, analisar como essa rede pode ter uso informativo e educacional? Como a aprendizagem poderá acontecer no contexto da mobilidade e da conexão dos aplicativos? E como possibilitar ao sujeito a construção do seu conhecimento tanto individualmente quanto coletivamente?

Evidencia-se então que a qualidade está diretamente ligada à satisfação do usuário e que esta pode ser percebida de formas diferentes. Mas se faz mais importante destacar que existem aspectos básicos que servem de parâmetros de avaliação para qualquer tipo de software. No caso dos aplicativos com fins educativos, esses parâmetros incluem características pedagógicas e aquelas relacionadas aos aspectos técnicos. Um aplicativo não deve, obrigatoriamente, conter todas as car- 
acterísticas de qualidade, e sim, ter a qualidade necessária para o alcance de seus propósitos e satisfação de seus usuários.

Já no que se refere ao conteúdo, ressalta-se que a escolha de um aplicativo provoque reflexões sobre como ele poderá contribuir para que o aluno construa seu conhecimento e, ainda, em que tipo de proposta pedagógica poderá ser utilizado. Sem esquecer dos aspectos relevantes a assimilação de conteúdos tais como uma apresentação de forma objetiva, priorizando a interatividade e a criatividade, fornecendo sempre feedback, sendo estimulante, provocativo e desafiador para reter a atenção de todos os alunos.

Segundo teóricos como Saccol, Schlmmer, Barbosa (2011) não se foi consolidada até o momento da pesquisa, uma "teoria da aprendizagem com mobilidade", o que precisamos então para fundamentá-la é de uma adequação pedagógica em relação às escolhas tecnológicas e de uma adaptação coerente às teorias existentes.

Umas das teorias que se adaptam a argumentação favorável a essa mediação tecnológica no aprendizado inclusivo é a Teoria da Atividade de Leontiev (1978), tomando como princípio a ação de um sujeito mediada por uma ferramenta e destinada a um objetivo. Essa atividade é direcionada por um motivo principal que envolve a realização de diversas ações que são compostas por operações desenvolvidas de forma individual ou coletiva.

Outra teoria que também se adéqua a modernização de estratégias no ensino é o Construtivismo proposto por Piaget (1974), ao preconizar que a construção do conhecimento acontece através de uma interação do sujeito com o seu meio e sua aquisição de conhecimentos depende tanto das estruturas de pensamento inerentes ao próprio sujeito, como de sua relação com o objeto, construindo assim um novo conceito. Ainda segundo o autor, "O conhecimento não se origina da experiência única dos objetos, como defende o empirismo, mas de construções sucessivas com elaborações constantes de estruturas novas”. De acordo com as teorias os requisitos pedagógicos estão relacionados às estratégias de apresentação das informações e tarefas exigidas no processo da inserção ao novo.

Figueiredo (2005) enumera as seguintes características que podem ser consideradas como requisitos pedagógicos para o levantamento adequado de aplicativos educacionais: contexto de aprendizagem, modelo e objetos de aprendizagem que o aplicativo privilegia; adequação aos conteúdos curriculares, pertinência em relação ao contexto educacional a uma disciplina específica ou ao trabalho interdisciplinar; aspectos didáticos, clareza e precisão dos conteúdos, recursos motivacionais, tratamentos de erros; mediação pedagógica, atuação docente na mediação entre conteúdo e contexto de aprendizagem; e, facilidade de uso, que evidenciam o nível de facilidade de utilização do aplicativo, incluindo a facilidade dos usuários em aprender a usá-lo. Tendo esse ultimo fator como algo recorrente em todas as literaturas sobre usabilidade.

Dentro da perspectiva de criação de conhecimento e de aprendizagem, tem se debatido sobre a capacidade de uma organização educacional adquirir, assimilar e aplicar conhecimentos de fontes externas para gerar melhor desempenho interno. Para autores como Muller-Seitz e Guttel (2013) os relacionamentos colaborativos fortalecem a capacidade de absorver conhecimentos, compartilhar e trocar estratégias.

A fim de melhorar essa capacidade absortiva, ou seja, a fim de melhorar uma instituição de ensino nos quesitos de inclusão, por exemplo, pode-se estabelecer vínculos com outras instituições de ensino ou outras organizações de interesse para, assim, expandir sua base de conhecimentos e também enriquecer a qualificação e as experiências de seus funcionários e colaboradores.

Deste modo, a ação de compartilhar com outras instituições de ensino, informações, opiniões, colaborações e mobilizações sobre um tema ou projeto pedagógico para potencializar a educação inclusiva, confrontando competências e saberes já existentes, proporciona efetivas condições para ampliar o conhecimento inicialmente criado em uma dada escola ou em um dado contexto específico. Esse processo inicia-se no nível individual e, mediante a interação entre o conhecimento tácito e explicito, entre os indivíduos, entre os grupos e entre as organizações, o nível de conhecimento passa a ser mais completo, mais fundamentado, mais experienciável e mais significativo.

Considerando todo esse levantamento bibliográfico para a construção e a aplicação de soluções de aprendizagem com mobilidade, é necessário que estes aplicativos educacionais devam priorizar os critérios de usabilidade, acessibilidade, mobilidade, colaboração/cooperação pedagógica.

Com isto, foi possível agrupar estes critérios em quatro categorias, conforme a tabela abaixo, e destacar que os itens poderão constituir um instrumento como uma espécie de pontuação e compor um método para avaliação de aplicativos para dispositivos móveis. 
Mobilidade; Interação;

Aprendizagem e Habilidades; Lazer e Tarefas Cotidianas

Pedagógica

Contexto de aprendizagem; Adequação aos currículos; Aspectos Didáticos e Mediação

Pedagógica

Usabilidade

Facilidade de uso; Acessibilidade; Adaptação ao usuário; Aceitação; Resistência e Segu-

rança; Satisfação; Tempo de navegação

Comunicação Compartilhamento; Ubiquidade; Colaboração

Tabela 1: fonte autor

$\mathrm{Na}$ análise da tabela, os tipos de aplicativos (Mobilidade; Interação; Aprendizagem e Habilidade; Lazer e Tarefas Cotidianas) demonstram as possíveis vertentes que o m-learning pode atuar na inclusão, é pretendido também nessa categoria distinguir e organizar essa tipologia para cada deficiência específica, com o objetivo de direcionar os aplicativos para cada necessidade de docência, amparando tanto os professores que lidam com um único tipo de deficiência quanto os que lidam com várias delas.

As categorias pedagógicas (Contexto de Aprendizagem; Adequação aos Currículos; Aspectos Didáticos; Mediação Pedagógica) demonstram as estratégias de apresentação das informações que foram levantadas pelos teóricos já citados, já as categorias de usabilidade (Facilidade de uso; Acessibilidade; Segurança; Satisfação; Tempo de Navegação) demonstram as qualidades intrínsecas dos aplicativos, destacando as características que mais se repetiam nos estudos de adequação ao uso, juntamente aos fundamentos encontrados nos princípios do Design Universal e das Normas NBR ISO/IEC 9126.

As categorias relacionadas à comunicação (Compartilhamento; Ubiquidade; Colaboração) vem a ser a maior contribuição da pesquisa, visto que é através delas que promoveremos o conhecimento dos aplicativos educacionais para aulas inclusivas, promoveremos também mais pesquisas evidenciando essa temática de estudo e promoveremos o incentivo as trocas e disseminações de informações inclusivas feito uma rede solidária nas mídias digitais. A ubiquidade vai integrar os alunos ao seu contexto de aprendizagem e ao seu entorno social, família e amigos; a colaboração, fundamentada pelos projetos de design centrados nos usuários, que exigem a ação participativa e dialógica entre professores, alunos e institu- ições de ensino; e por fim, o compartilhamento, que socializa o desenvolvimento das atividades, e seus possíveis resultados, positivos ou negativos, provocando uma troca de conhecimentos e experiências de ações de inclusão.

Podemos observar que cada categoria apresenta suas próprias características e especificidades. Estas podem ser explicitadas e discutidas de modo que os diferentes tipos de aplicativos possam ser adotados nas situações de ensino-aprendizagem que mais se adéquam. Além disso, as categorias e os critérios permitem um maior número de análises que, certamente, atenderão um maior número de usuários e suas necessidades de avaliação de aplicativos.

Neste projeto, existe a vontade de mudança, assim como existem métodos de educação inclusiva ao redor dos aplicativos de acessibilidade. O que falta é um meio efetivo de divulgação, de engajamento e de aplicação de tais ideias, além de um maior diálogo entre profissionais da área para que possam trocar histórias, compartilhar experiências e crescer juntos em prol da educação inclusiva.

\section{Como engajar em rede para o compar- tilhamento do uso de aplicativos de acessibilidade}

A tecnologia promove uma conexão que engaja e transforma a comunicação numa espécie de "boom" da informação participativa e colaborativa, tendo as redes sociais e os aplicativos com grande protagonismo nesse fenômeno. Essas inúmeras possibili- 
dades de interação geram mudanças de hábitos nos quais as pessoas se informam sobre tudo e todos de forma integrada e digital, os tornando consumidores e agentes da comunicação.

Para Terra (2016) a comunicação digital em redes sociais presume mais aceitação de diálogos, conversações e colaborações, além de uma simetria entre emissores e receptores estabelecendo uma constante troca de papéis entre eles. Ou seja, as interações em redes sociais digitais possibilitam a aproximação e o empoderamento dos sujeitos, criando-se assim, uma nova esfera pública, um novo território que ainda se depara em processo de compreensão pelas Ciências Sociais, cunhado por Felice (2007) como o "social tecnológico".

Uma das particularidades de mais destaque da sociedade no século XXI é sem dúvida essa descentralização do "poder de fala", antes restrito às grandes organizações e grandes mídias, e hoje, passível de compartilhamento por qualquer pessoa em decorrência do atual contexto tecnológico. Todos os sujeitos possuem acesso a ferramentas para assumir seu protagonismo comunicacional em benefício de suas crenças, valores e temas de preferência.

A chamada era da informação em conexão, caracterizada pela revolução centrada nas tecnologias digitais de informação e comunicação, coincide com a emergência de uma estrutura social em redes que se encontram em todos os âmbitos da atividade global interdependente. De acordo com Correa (2016) a digitalização da sociedade é um processo irreversível, "que reconfigura o tradicional processo de comunicação, no qual emergem a participação, a colaboração e o espaço para expressão de múltiplas vozes".

Essa interação de vozes são compreendidas como um espaço de discussão e ação social entre as pessoas. Constituindo-se em um local de conversa e decisões coletivas a partir das trocas de ideias a respeito de assuntos de interesse geral, nesses debates encontram-se também temas de grande relevância para a sociedade, tais como os de interesse desse artigo que envolvem a educação e a inclusão.

Hoje em dia, a mídia e a tecnologia como foi exposto, fornecem ferramentas nas quais o conhecimento pode ser arquivado, processado e transmitido fluidamente por todos. Segundo Judelman (2004) estamos conectados por meio de redes globais, nas quais milhões de usuários de computadores estão compartilhando e distribuindo informações contidas na internet. O desafio, entretanto, se enquadrada na gestão e no direcionamento desse conhecimento em conexão para que ele possa chegar e atender as demandas sociais que se pretende atingir.

Mas como conviver e assimilar essa quantidade de dados em camadas participativas que permeiam o fazer comunicacional nas práticas contemporâneas?
Nas redes só se escolhem conteúdos que tiverem valor agregado ou souberem narrar seu contexto com criatividade e inovação, tanto do ponto de vista visual quanto das estratégias comunicacionais e organizacionais das ideias oferecidas.

Já que no meio digital, o que vem a atrair os leitores são a qualidade do conteúdo e a experiência que cada página ou interface consegue os oferecer, desenvolvendo uma audiência popularizada por visualizações, curtidas e compartilhamentos. À vista disso, as páginas e aplicativos que dominam a produção e distribuição de conteúdos digitais conseguem operar como formadoras de opinião do seu público-alvo e como ferramentas de construção de base de dados precisos.

De acordo com o levantamento da Brazil Digital Future in Focus da ComScore (2015) os usuários brasileiros permanecem entre os mais engajados do mundo, sendo que as redes sociais são onde os brasileiros gastam mais tempo se mobilizando e discutindo sobre vertentes de interesse público. Seu tempo gasto nas redes sociais é 60\% maior que a média mundial e dentre as redes sociais mais utilizadas no Brasil, o Facebook lidera com $78 \%$ da preferência.

Portanto, para ser uma estação de mídia de reconhecimento com conteúdos de inclusão que realmente façam a diferença na educação, é preciso conquistar a atenção em meio à dispersão das timelines. Segundo Ferrari (2016) as redes sociais, principalmente o Facebook estão se tornando a nossa fonte de informação escrita e televisiva diária, somados aos costumes de compartilhamento que a plataforma nos estimula, fazendo de uma mera postagem informativa uma grande propagação de interpretações, debates, opiniões e trocas de conhecimentos que são medidos e popularizados em discordâncias e concordâncias por curtidas ou emojis afetivos.

O Facebook tem conquistado os termos mais disputados do mercado atual, estabelecidos pelo tempo e pela atenção dos consumidores, afinal, essas duas palavras quando aplicados a qualquer produto ou serviço representam o quanto as pessoas precisam, gostam e são viciadas em algo. Beguoci (2015) afirma que embora as pesquisas sobre comportamento e uso do tempo tenham muitas diferenças entre si, há evidências claras que o Facebook está substituindo, tanto no Brasil como nos EUA, os veículos de comunicação atuando como o primeiro lugar de pesquisa em que as pessoas vão para saciar suas dúvidas e saber o que está acontecendo no mundo.

No inicio, as marcas jornalísticas resistiram ao Facebook e algumas resistem até hoje, em contra ponto a isso os veículos de comunicação começaram a depender muito do tráfego de informações que vem das redes sociais, o eixo de atenção para a pes- 
quisa de notícias e de entretenimento, mudou.

Moherdaui (2016) em sua investigação sobre o jornalismo de dados descobriu que as timelines das redes sociais do Facebook e do Twitter não têm manchetes e nem foram pensadas para replicar o formato da mídia clássica demarcado pela diagramação de suas notícias. Seu diferencial informativo está justamente no excessivo fluxo de notícias, havendo a impressão de que os informes se embaralham e se perdem em meio as suas interfaces. Porém, as suas estratégias organizacionais se dão mediante o "tagueamento" colaborativo, que vem da expressão em inglês collaborative tagging, atividade na qual podem ser incluídos e interligados metadados sob a forma de tags ou hashtags que além de sistematizar a busca, nos direcionam a mais noticias relacionadas à pesquisa em questão.

O "tagueamento" colaborativo consolida e organiza dados sobre informações completas para curiosos em determinado tema, ajudando significativamente o processo de democratização e divulgação das noticias, palavra esta que carrega muito poder na formação de opinião das pessoas. São justamente por meio delas, das boas e bem "tagueadas" notícias que promoveremos a conscientização necessária para o reconhecimento das ferramentas tecnológicas com a finalidade de auxiliar a comunicação e a educação na inclusão.

Acredita-se que esse empreendedorismo digital passa por projetos com uma visão antropológica da comunicação, encarando a realidade como o Facebook e muitos outros aplicativos que aliam base de dados, inteligência coletiva e vontade de mudar e melhorar a vida das pessoas. Nestes casos, os projetistas tratam da consciência de uso do sistema somada à estética da interação, resultando numa experiência única e individual em favor da cultura participativa na rede, apresentando iniciativas diferenciadas em aspectos de produção, distribuição e de relacionamento com as pessoas.

Esse tipo de serviço estabelece, portanto, um novo patamar de trocas entre os atores sociais, ao transpor sua capacidade inerente de engajamento dos públicos em prol dos seus objetivos específicos. As mídias digitais e sociais, quando bem elaborados, são capazes de ocupar espaços antes destinados somente às mídias tradicionais na formação de poder e opinião, abrindo, com isso, seu papel de facilitador da comunicação nos novos espaços de diálogo, de criação e de relacionamento com outras esferas de transformação social e cocriação de uma nova realidade.

Uma questão importante a ser considerada aqui é que este reconhecimento participativo pressupõe dos indivíduos mobilizados um grau mais profundo de envolvimento, que perpasse a consciência da importância da causa e o mero interesse em contribuir, alcançando o nível de pertencimento e de corresponsabilidade, descritas por Henriques (2013) como:

[...] estratégias de mobilização, que ao almejarem a geração de vínculos deste tipo, buscam transcender as meras ações pontuais, circunstanciais. A condição para isso é o estabelecimento da coesão e da continuidade do projeto, que são a ponte entre a ação isolada e a ação responsável. Entretanto, a função básica de gerar e manter vínculos dos públicos com o movimento depende, para ser bem sucedida, do cumprimento de outras funções que devem estar devidamente integradas e articuladas, tais como difundir informações, promover a coletivização, registrar a memória e fornecer elementos de identificação com a causa e o projeto (HENRIQUES, 2013, p. 21).

Essas estratégias que demandam a disseminação e divulgação de conteúdos passam pela composição de uma cadeia de valor que deve ganhar assiduidade de uso e por consequência, aumentar a relevância de um aplicativo, serviço ou produto de inclusão para muitas pessoas.

A prática da curadoria de conteúdo, no caso, para a inclusão nas mídias sociais, de acordo com Ferrari (2016) permite consolidar conteúdo social sobre um determinado tema em muitas possibilidades. Podem ser textos, fotos, vídeos, não importa o formato. O que importa, contudo, é uma organização estratégica e um programa de distribuição contínuo, com indicadores de produtividade claros somados a visão de construção de uma boa reputação. É um pensar como curador. E, para tanto, é preciso se pensar na cadeia de valor como uma gestão de conteúdo no mapeamento de temas, formatos e fontes. Tanto material original quanto de terceiros - legitimamente apropriados - e colaborativo. A partir do escopo, surge a definição da grade de conteúdo e como esta será gerida ao longo do tempo nas mídias digitais.

Já na Curadoria e na edição entra o processo de seleção dentro do escopo determinando. Muitas vezes os curadores podem ser técnicos de um determinado tema (engenheiros, designers, economistas, estilistas, médicos, livreiros etc.) que vão olhar as fontes de conteúdo e selecionar de acordo com a "linha editorial" daquela organização (conjunto de crenças e valores). Daí o processo de edição fica a cargo de responsáveis pelo dia a dia, que vão cuidar da execução, de acordo com as fontes e com o volume de publicação pré-estabelecidos.

Além da amplificação e plataformas de distribuição das fontes e do processo de curadoria e edição, os canais de distribuição escoam de forma organizada esta produção. Pode ser via web, mobile, vídeo, aplicativos (APP) ou mesmo canais de terceiros, como redes sociais, utilizando amplificadores como publicidade nativa e mídia programática, com in- 
dicadores de produtividade bem configurados.

Talvez só mesmo um serviço "bem curado" movido para esse objetivo seja capaz de entregar, a essas pessoas que lidam e a essas que têm necessidades educacionais especiais, conteúdos e informações de forma fácil, organizada, contínua, consistente e integral.

\section{Considerações Finais}

Esse tipo de serviço estabelece, portanto, um novo patamar de trocas entre os atores sociais, ao transpor sua capacidade inerente de engajamento dos públicos em prol dos seus objetivos específicos. As mídias sociais, quando bem elaborados, são capazes de ocupar espaços antes destinados somente às mídias tradicionais na formação de poder e opinião, abrindo, com isso, seu papel de facilitador da comunicação nos novos espaços de diálogo, de criação e de relacionamento com outras esferas de transformação social e cocriação de uma nova realidade.

O que diferencia um simples processo comunicativo de uma curadoria conteúdista de mobilização social, na visão de Toro e Werneck (2004) é que além das pessoas formarem opiniões próprias e se dispuserem a agir, elas devem se sentir donas da informação. Nas palavras dos autores, para o sucesso de uma mobilização, é preciso que todos que dela participam tenham um comportamento comunicativo, "repassem-na, utilizem-na e tornem elas próprias fontes de novas informações”.
Na cultura da conexão, com ferramentas de distribuição de conteúdo e publicidade baseada no contexto de navegação e no comportamento dos usuários, é possível ser cada vez mais preciso na conquista de popularidade e na compreensão de como funciona essa nova economia do afeto e do sentimento nas redes, na qual a apropriada curadoria na utilização da mídia adquire um papel central.

Nesse sentido, é preciso tomar a publicidade e o design nas redes não só como elemento que pode auxiliar no trabalho de divulgação, mas como uma pedagogia, um conjunto sistemático de significados que criam, por meio da linguagem midiática, representações do mundo. A atividade, assim interpretada, pode ensinar no contexto da inclusão, por exemplo, como se comportar diante de determinada situação, como discutir e debater sobre políticas públicas para garantir direitos de igualdade à democracia plena $\mathrm{e}$ como ajudar no desenvolvimento da educação inclusiva por meio de aplicativos de acessibilidade.

É inquestionável que tais mídias possam possibilitar a maior participação nos debates de interesses públicos e, com isso, o estimulo a práticas inclusivas na educação, proporcionando uma relação mais estreita entre os professores e alunos com necessidades educacionais especiais. Como afirmam Mainieri e Ribeiro (2011) às temáticas sociais que antes da comunicação digital dependiam somente da boa vontade da mídia de massa para que se tornassem pautas e pudessem alcançar as pessoas interessadas ou as que viessem a se interessar, hoje podem caminhar de forma autônoma na busca por reverberação, tagueamento e engajamento social.

\#respeitomefazdiferente \#vemincluir \#app \#educaçao

\title{
Referências
}

BEGUOCI, Leandro. A reinvenção do Jornalismo. Disponível em: projetodraft.com. 2015

CORREA, E. S. A comunicação na sociedade digitalizada: desafios para as organizações

contemporâneas. In: KUNSCH, M.M.K (Org.). Comunicação organizacional estratégica: Aportes conceituais e aplicados. São Paulo: Summus, 2016.

\author{
COSTA, R. S.; FREITAS, H. O papel da confiança do decisor no processo decisório em \\ um contexto de risco. In: $8^{\circ}$ Congresso Internacional de Gestão de Tecnologia e Sistemas de \\ Informação - CONTECSI, 2011, São Paulo/SP. Anais do $8^{\circ}$ Congresso Internacional de Gestão de \\ Tecnologia e Sistemas de Informação - CONTECSI, 2011.
}


FELICE, $M$. As formas digitais do social e os novos dinamismos da sociabilidade contemporânea. In: KUNSCH, M. M. K; KUNSCH, W. L. (Orgs.). Relações públicas comunitárias: a comunicação em uma perspectiva dialógica e transformadora. São Paulo: Summus, 2007.

FERRARI, Pollyana. Comunicação digital na era da participação. (recurso eletrônico) / Pollyana Ferrari -- Porto Alegre, RS: Editora Fi, 2016.

FIGUEIREDO, C. X. et al. Avaliação de software educacional. Lavras: Universidade Federal de Lavras, 2005.

HENRIQUES, M. S. Comunicação e estratégias de mobilização social. 3a ed. Belo Horizonte: Autêntica, 2013.

JUDELMAN, G.B. Knowledge Visualization - Problems and Principles for Mapping the Knowledge Space. M.Sc. thesis, University of Lübeck, Germany, 2004.

LEONTIEV, A. N. Activity, consciousness, and personality. Englewood Cliffs, NJ: PrenticeHall, 1978.

MAINIERI, T.; RIBEIRO, E. M. A. O. A comunicação pública como processo para o exercício da cidadania: o papel das mídias sociais na sociedade democrática. Revista Organicom. São Paulo: Universidade de São Paulo, ano 8, n. 14, p. 49-61, 10. Sem. 2011.

MARTINS, Rosilene Maria Sólon Fernandes. Direito á Educação: aspectos legais e constitucionais. Rio de Janeiro: Letra Legal, 2004.

MOBILE: Native Apps, Web Apps, and Hybrid Apps. Disponível em: http://www.nngroup. com/articles/mobile-native-apps/. 2013.

MULLER-SEITZ, G; GUTTEL,W. Toward a choreography of congregating: a practicebased perspective on organizational absorptive capacity in a semiconductor industry consortium. Management Learning. 2013.

PIAGET, Jean. O Direito à Educação no Mundo Atual. Para Onde Vai a Educação? Trad. Ivette Braga. Rio de Janeiro: José Olympio, 1974.

SACCOL, A., SCHLEMMER, E., BARBOSA, J. M-learning e u-learning: novas perspectivas das aprendizagens móvel e ubíqua. São Paulo: Pearson Prentice Hall, 2011.

SILVA, M. G.; BATISTA, S. C. F. Metodologia de avaliação: análise da qualidade de aplicativos educacionais para matemática do ensino médio. Revista RENOTE, v. 13, n. 1, jul. 2015 .

STORY, M. "Principles of Universal Design”. In Universal Design Handbook, edited by E. Ostroff and W. Preiser. New York: McGraw-Hill. 10.3-10.19, 2000. 